\title{
Crítica dunha identidade sentimental de Galicia: sentimento, razón e historia en Daniel Cortezón
}

\author{
Critique of Galicia's Sentimental Identity: Sentimentality, History \\ and Reason in Daniel Cortezón
}

\author{
Santiago SanJURJo Díaz
}

Universidad Complutense de Madrid

Departamento de Filología Alemana

santiago.sanjurjo@ucm.es

[recibido 31/10/2014, aceptado 02/02/2015]

\section{RESUMO}

O presente artigo constitúe unha primeira achega ao estudo da crítica filosófica e política da idea sentimental de Galicia que levou a cabo Daniel Cortezón (1927-2009) na súa obra ensaística. Partindo da análise de Helena MiguélezCarballeira no seu Galicia, a Sentimental Nation (2013) estúdanse os conceptos de sentimento, historia e razón nos principais textos teóricos do autor, incluíndo algúns inéditos.

PALABRAS CHAVE: Identidade, sentimentalidade, historia, razón, nación.

\section{RESUMEN}

El presente artículo constituye una primera aportación al estudio de la crítica filosófica y política de la idea sentimental de Galicia que llevó a cabo Daniel Cortezón (1927-2009) en su obra ensayística. Partiendo del análisis de Helena Miguélez-Carballeira en su Galicia, a Sentimental Nation (2013) se estudian los conceptos de sentimiento, historia y razón en los principales textos teóricos del autor, incluyendo algunos inéditos.

PALABRAS CLAVE: Identidad, sentimentalidad, historia, razón, nación.

\section{ABSTRACT}

This article offers a first contribution to the philosophical and political criticism surrounding the sentimental idea of Galicia in the essays of Daniel Cortezón (1927-2009). Using Helena Miguélez-Carballeira's analysis in Galicia, a Sentimental Nation (2013) as a starting point, the investigation explores notions of sentimentality, history and reason in Cortezón's key theoretical writing, including several unedited texts.

KEY WORDS: Identity, sentimentality, history, reason, nation.

SAnjurjo Díaz, S. (2015): “Crítica dunha identidade sentimental de Galicia: sentimento, razón e historia en Daniel Cortezón”, Madrygal (Madr.), 18, Núm. Especial: 139-146.

SUMARIO: 1. Introdución. 2. A identidade sentimental de Galicia. 3. Fundamentos da crítica dunha idea sentimental de Galicia. 4. Referencias bibliográficas. 


\section{INTRODUCIÓN}

Ao acudirmos ás máis correntes e usuais obras de consulta e referencia sobre literatura galega do século XX coa intención de profundar na obra do escritor ribadense Daniel Cortezón, cuxo quinto cabodano se cumpriu en outubro de 2014, a principal sensación coa que ficamos é a de decepción. Así, no libro colectivo Literatura galega: século $X X$, editado por A Nosa Terra, aparece mencionado tan só en catro ocasións: tres delas como un membro máis de exhaustivas listaxes de autores e outra consignándoo como autor dunha novela alegórico-social (cf. Bernárdez 2001: 229, 255, 371 e 406). Poucos máis datos achega a Historia da literatura galega de Dolores Vilavedra, quen só fai referencia á súa faceta menos descoñecida: a de dramaturgo. Así, segundo Vilavedra, Cortezón é un autor de teatro social que "recorre sen complexos ó método brechtiano para realizar unha lectura crítica dos feitos históricos en pezas como Prisciliano (...) ou $O s$ Irmandiños (...)" (Vilavedra 1999: 263). Non só esquece a distinción que o propio autor fai entre un teatro histórico-político e outro político-social (cf. Cortezón 1971: 35), senón que simplifica a complexa relación do dramaturgo galego coa obra do autor alemán, obviando declaracións como a de que o seu é un "teatro épico -non no senso brechtiano, por suposto-" (Cortezón 1978: 11).

A sensación de decepción medra ao tentarmos atopar máis datos sobre o seu inxente labor ensaístico, que normalmente fica reducido a unha simple enumeración dos seus títulos. Só en moi contadas ocasións ten lugar o milagre, como ocorre no estudo que escribiu Anxo Abuín co gallo da montaxe do Xelmírez, que, dirixido por Roberto Vidal Bolaño, fixera o CDG en 1999. Abuín sinala que, para entender mellor a obra literaria de Cortezón, "é imprescindible a análise dun dos seus textos máis densos e cheos de erudición, o ensaio $D e$ la saudade y sus formas" (Abuín 1999: 84).
Porén, a tendencia dominante é a de fuxir ante a densidade e erudición anteditas, como así o demostran unhas recentes e, ao noso xuízo, non demasiado afortunadas declaracións feitas ao xornal asturiano La Nueva Espa$\tilde{n} a$ polo actual presidente da Real Academia Galega, quen considera a excelente biografía do intelectual Dionisio Gamallo Fierros que Cortezón publicou en 2005, un libro "muy de filosofía, pero no didáctico para conocer más de su obra"1.

Así pois, observamos que a súa faceta de ensaísta apenas achou recoñecemento no ámbito da crítica e da historiografía literaria galega, que semella estar máis preocupada pola formación autodidacta e pola súa actividade como "aprendiz de mancebo" de botica que polo seu pensamento. Esta falla resulta particularmente grave dado que, despois de termos lido de xeito exhaustivo a obra de Cortezón, podemos constatar o feito de que toda ela constitúe unha unidade que gravita arredor dun obxectivo fundamental e que non se pode comprender de xeito cabal sen telo en consideración e que aquí chamaremos "a crítica dunha identidade sentimental de Galicia". Así o afirma o propio autor nunha entrevista concedida a Roberto Pascual:

Por aquel tempo (refírese aos anos 60) afírmome no meu rexeite do sentimento da saudade, do permanente salaio histórico e do nihilismo esencial polas súas características vitais (...).

Comecei, pois, con traballos teóricos en procura das súas posibilidades liberadoras do salaiante espírito do rústico... (Pascual 2008: 202)

A finalidade da presente achega consiste en demostrar que Cortezón foi un dos primeiros críticos daqueles discursos que, na posguerra, contribuíron a crear e difundir unha identidade sentimental galega. Así, trazarase un primeiro bosquexo cronolóxico dun posicionamento teórico que arrinca ben cedo cos ensaios inéditos $O$ esprito da Galiza (1955)

\footnotetext{
${ }^{1} \mathrm{Cf}$. http://www.Ine.es/asturias/2014/08/25/xesus-alonso-gamallo-trato-transmitir/1632927.html (consulta: $31 / 10 / 2014)$.
} 
e Pantocritica galiciana y otras cuestiones (1956), e que desde entón ocupará ao autor ribadense. Coa esculca da pegada das consideracións sobre os conceptos de sentimento, razón e historia nos diferentes textos teóricos de Cortezón, explicaremos como esta teima antisentimental constitúe, talvez, a súa meirande e máis orixinal achega, aínda por estudar a fondo, á cultura galega ${ }^{2}$.

\section{A IDENTIDADE SENTIMENTAL DE GALICIA}

No seu libro de 2013, Galicia, a Sentimental Nation, Helena Miguélez-Carballeira desenvolve a tese de que

the trope of Galician sentimentality as a marker of national indentity has appeared repeatedly in modern representations of the region, its language and its people, forming a continuum that extends throughout the textual and visual corpus on Galician history and culture from the late ninteenth century up until present times. (2013: 2)

Esta condición sentimental de Galicia, complexa e variable, pode, porén, condensarse "on the assumption that Galicians are a nostalgic people, living in harmonious communion with their landscape or yearning for its beauty if away from it", o que lles atribuiría "an innate capacity for poetry and an aloof humour, a way of being in the world that is both impractical and unrealistic, but also astute and reserved" (2013: 2).

Lonxe de entrar a valorar o papel deste discurso para as diferentes políticas nacionalistas, Miguélez-Carballeira emprega unha perspectiva poscolonial e feminista para levar a cabo unha exhaustiva e profunda análise das orixes en políticas coloniais e de xénero desta formulación identitaria.
Así, por unha banda, a autora demostra de xeito convincente que o "estereotipo do sentimentalismo galego" está inzado de adxectivos que "constantemente remiten aos valores da feminidade patriarcal: lirismo, dozura, tenrura, pasividade, modestia, humildade, irracionalidade, vaidade" " Ademais, neste discurso, o idioma galego "é retratado como unha lingua tenra e melodiosa" e a rexión e a súa xente quedan transfiguradas nunha "entidade feminina, sentimental" que, de xeito innato, é incapaz de toda acción violenta (2013: 55). Deste xeito, establécese unha "correlación entre feminidade e sentimentalidade", que serve para desmantelar "alternative discourses of Galician sentimentality as a positive national narrative in circulation during the second half of the nineteenth century" (2013: 55).

Por outra banda, e atendendo ás implicacións coloniais da xénese da "sentimentalidade galega", Miguélez-Carballeira sinala o carácter ambiguo do estereotipo sentimental, xa que se ben foi empregado para "desarticular unha cultura nacional insurxente á vez que facilitaba un espazo para a súa diferenza controlada", tamén resultaba útil para un "programa da cultura nacional oprimida" na súa procura da "autodiferenzación e expresión" (2013: 5). Porén -e isto vai resultar imprescindible para entender o pensamento de Cortezón-, Miguélez-Carballeira engade que a finais do século XIX, o tropo da sentimentalidade "would be reappropriated by centralist positions as a colonial stereotype with which to stall the political articulation of Galician national insurgence" (2013: 13). Segundo este discurso, os galegos posuirían así unha "natureza estática e pasiva", o cal "forms the psychological legacy of Galicia's Celtic past, and hence of its populations' collective resignation to a state of subjugation" (2013: 21).

\footnotetext{
${ }^{2}$ Queremos expresar publicamente o noso profundo agradecemento a Matilde González por ternos posibilitado o acceso ás obras inéditas de Daniel Cortezón. Ademais, reproducimos de xeito fidedigno os textos, respectando as particularidades ortográficas dos orixinais, tanto en galego como en castelán.

${ }^{3} \mathrm{Cf}$. http://www.somosninguen.org/unha-nacion-sentimental-entrevista-a-helena-miguelez-carballeira/ (consulta: $31 / 10 / 2014)$.
} 
Miguélez-Carballeira traza un percorrido polas voltas e reviravoltas da identidade sentimental de Galicia e as súas implicacións políticas ao longo da súa complexa evolución, desde Murguía ou Leandro de Saralegui, ata Alberto Núñez Feijóo, pasando por González Besada, Carré Aldao, Couceiro Freijomil ou Carvalho Calero; mais para o noso obxectivo interesan particularmente as reflexións sobre Ramón Piñeiro e o grupo Galaxia. Como ben apunta a autora, este círculo intelectual consideraba de "primordial importancia para a preservación dun discurso galego de diferenza nacional" a "theorization of Galicians' differentiated psychological make-ups, for which the trope of sentimentality (encapsulated in the concept of Galician saudade) served as a channel" (2013: 26-27). Miguélez-Carballeira sinala que "un aspecto do discurso do piñeirismo" que ás veces pasa desapercibido é o de que as "chief metaphors shared a history with those repeatedly utilized in centralist/colonialist depictions of Galician identity" (2013: 27). Así, nos textos de Piñeiro, "the trope of Galician sentimentality emerges as a conglomerate of images whirling around a twofold metaphorical construct", segundo o cal a identidade galega é algo "inextricably entwined with the land and landscape on the one hand, and with lyricsm on the other" (2013: 192), e deste xeito contribuíu a desactivar "the political project for Galician nationalism that Castelao and others represented" (2013: 193). É neste contexto onde hai que situar a crítica de Cortezón, para quen, como imos ver, a identidade sentimental é a principal responsable do que el considera o fracaso histórico de Galicia e do conformismo da meirande parte do seu pobo:

Gran parte de la intelectualidad nacionalgalleguista ha estado justificando nuestro proceso de autonihilación nacional; alentando con lirismos vacíos e[1] durmiente espíritu "saneroniano" que, a la vez[,] reprochamos en nuestro himno; por ejemplo: la saudade en su versión existencialista, destructiva (mi silenciado ensayo "De la saudade y sus formas", 1958, atacaba el problema). (Gómez 2005: 4)

Agora pasaremos a ver en que termos e con que finalidade leva Cortezón a cabo este ataque.

\section{FUNDAMENTOS DA CRÍTICA DUNHA IDEA SENTIMENTAL DE GALICIA}

No seu breve mais fundamental ensaio Sobor das condicións do asalto á razón (1990), Cortezón, converténdose só por uns intres nunha sorte de menciñeiro, presenta unha fórmula para preparar a apócema do "espírito galego":

Engádase ben remexido o seu anaco de lirismo tebroso-patético-salaiante có correspondente adobío de saudade a máis dunha boa presada de humor, renarteiría e xorne para supera-la impotencia, seu chisco de cántiga de escárneo e maldicer e velaí que o potaxe arquetípico, ou máis ben a ola pobre da ánima e do ánimo galego está servida. (Cortezón 1990: 26)

Porén, esta receita só é cabalmente comprensible se se pescuda a longa e complexa traxectoria da análise desmanteladora da idea sentimental de Galicia que, como ficou indicado na introdución, Cortezón aborda desde os comezos da súa actividade ensaística. Así, xa na súa obra $O$ esprito de Galiza (1955) -que contén in nuce os principais puntos de vista do autor ao respecto-, recorre ás hoxe máis que cuestionables concepcións e terminoloxías dos historiadores conservadores Oswald Spengler e Arnold J. Toynbee para tratar de definir unha identidade "esencial" de Galicia. No capítulo segundo, titulado "O senso yin da cultura galega", afirma que "[t]odol-o que hai de máis profundo, e de mellor, n-a i-alma de Galiza, é yin, femíneo" (1955: 31). Este "espírito femíneo" estaría caracterizado por unha serie de atributos como o seu proceder "máis por intuiciós sentimentales que por eiscoxitaciós razonables" (1955: 31), a súa "ollada cósmica", a súa "pasividade", que cristaliza nunha "tendencia á inmovilidade", así como o seu carácter "típicamente rural" (1955: 32-33). Ademais, Cortezón insiste na oposición entre sentimento e razón ao afirmar que "certamentes non atoparemos nin un átomo de lóxica n-o esprito femíneo... coma non-o atoparemos tampouco n-as primordiaes manifestaciós do esprito sustanza de Galiza" (1955: 33). Como salta á vista, e corroborando as teses de Miguélez-Carballeira, o debate sobre a identidade sentimental de Galicia ten lugar, tamén nesta ocasión, no marco 
dunha retórica e a uns discursos ancorados nun imaxinario cunha profunda raizame patriarcal que -é de xustiza dicilo- Cortezón abandona paulatinamente nos textos posteriores.

É preciso advertir que as características que Cortezón está describindo de forma crítica como propias do suposto "espírito galego" coinciden case exactamente coa visión esencialista que tiña, por exemplo, un Risco. Na súa Teoría do nacionalismo galego, no capítulo titulado "A mentalidade galega", atopámonos con afirmacións como: “(...) Temos dos britanos, o humorismo, temos dos franceses o senso crítico; temos noso, o lirismo e a saudade. Tres calidades que caracterizan a alma romántica (...). Foi co romanticismo co que rexurdiu a cultura galega" (Risco 1994: 32). Tamén Cortezón, citando a Castelao, para quen "Castela é a lóxica e Galiza a intuizón e o sentimento" (1955: 41), afirma que "o lirismo é a citra caraiterísteca do xénio galego. (...) O lirismo é a forma individoal e persoal de intuir o mundo circondante" (1955: 48-49).

Seguindo coa caracterización do "senso yin" do espírito galego, Cortezón, que opina que a "i-alma galega é unha i-alma de rus" (1955: 47), rural, tamén se fai eco do que Risco chama "adoración á Terra" ou "emoción do sedentarismo", xa que destaca a "tendenza car-á inmovilidade" e o "pecuniar pneuma pasivo", estoico, "senequista" do carácter galego, así como a ausencia dunha "aititude agresiva", sumada a un humorismo que é "outra d-as eispresiós do senso defesivo do home galego" (1955: 123), á súa "ataraxia" e á súa "capacidade de resistenza", afástana dunha "aititude yang capás de defender, co azo agresivo, a súa eisistenza pirmeiro, e de faguer seu proprio ámpito hexemónico dimpois. E iso é o que hai que labourar, se é que se ten a vidalidade imprescindíbel pra repersentar un dino papel n-a hestoria hispán" (1955: 35-36). E máis aínda: Cortezón considera que "o predomiño do sentimento e d-as formas do coñecimento intuitivo encor do racional é unha custante da pneumatoloxía galega", e a isto habería que opoñer un "senso yang" que "é imprescindíbel crear" (1955: 114) para introducir -e isto resulta clave- unha "certa modificación n-as eispresiós da vida galega, e doarlles certo grado de agresividade" que "non pode xurdir do senso yin da eisistencia" (1955: 112). Sen el, sen a existencia dun "pulo hestórico" vital e dirixido a un obxectivo e sen "ideais-forzas", non hai nación, xa que esta "é sempre un produito da lóxica hestórica dirixida por un epicentro hexemónico co azo e ideias-forzas" (1955: 128-129).

$\mathrm{O}$ derradeiro capítulo d'O esprito de $\mathrm{Ga}$ liza, titulado precisamente "A Saudade", semella constituír a primeira das moitas aproximacións que fixo o noso autor ao concepto da saudade, que, como sinalaba MiguélezCarballeira, condensa a "idea sentimental" de Galicia do piñeirismo, e é descrito como "a capacidade que os galegos teñen para un sentimento non continxente, universal" (2013: 193). Cortezón semella estar de acordo coas palabras de Xohán V. Viqueira que cita Risco no apartado "O sentimento galego" da súa xa mencionada Teoría do nacionalismo galego: "Queredes unha verba (...) que vos diga en resume o noso lirismo e a nosa alma? Aí a tedes: saudades, ou como tamén dixo Rosalía, delas predilecta, soidades (...)" (Risco 1994: 33). Para o ribadense, a saudade "é o máis decisivo e siñificativo dato do esprito galego" (1955: 140), o que para el non deixa de ser un dato moi negativo, posto que este sentimento, que non é senón a resposta do home galego "á chamada biolóxica do seu instinto yin" (1955: $144)$, "ven a ser a eispresión lírica do esprito pesimista galego". A saudade, que Piñeiro definira como un sentimento que "carece de referencia a un obxecto" (Piñeiro 2001: 36), é ademais a "'misticidade' razal do galego: un pobo que non ten unha misticidade relixiosa" (1955: 145) e, apuntando a unhas probables consecuencias que tería para o proxecto histórico de Galicia como nación, Cortezón fai fincapé na necesidade de estudar as "relacións posíbeles entre o autonihilismo do místico e o que Ortega chamou, n-a España invertebrada, 'nihilismo nacional' galego" (1955: 155).

Como se pode comprobar, xa no primeiro ensaio teórico que Cortezón dedica á cultura galega, fica establecida unha ecuación que identifica esa identidade sentimental cunha serie de aspectos negativos, pesimistas e irracionais que coutan e impiden o progreso 
histórico de Galicia. Asemade, é imprescindible resaltar que n'O esprito de Galiza xa aparece o que, ao noso xuízo, é un dos aspectos máis orixinais e decisivos do pensamento cortezoniano: se ben participa, como sinalamos, dunha serie de discursos de tenor esencialista sobre un presunto ser, neste caso sentimental, de Galicia, Cortezón está dando a entender, dun xeito máis ou menos velado que irá explicitando en textos ulteriores, que esas supostas "esencias" non son senón reflexos de intereses e loitas ideolóxicas, que deben ser sometidas a unha análise crítica para poder "construír" e "crear" identidades alternativas. Así, Cortezón, ofrecendo o que ao seu parecer é unha "interpretación que adoita diferir da defendida pola historiografía autoxustificativa da aldraxe e do asoballamento do galeguismo en xeral e do 'nacionalgaleguismo' en particular" (Cortezón 1999a: 29), adiántase nun feixe de décadas a teorías que apostan por un carácter "construído" e, xa que logo, "construíble" das nacións:

la nueva historicidad gallega, la que es preciso encauzar y proyectar en el futuro, ha de partir, precisamente, de una nueva serie de valores, y un rechazo de aquéllos que, por significar una acentuación de sus calidades negativas y avitales, la condujeron al enquistamiento tradicionalista y a la inhibición histórica. (Cortezón 1960: 167)

No seguinte texto teórico do que nos imos ocupar, o tamén inédito Pantocrítica galiciana y otras cuestiones (1956), Cortezón afonda máis nas implicacións que ten a identidade sentimental de Galicia, identificable coa tradición, para a súa historia, que el considera "la más fiel imagen del más estrepitoso fracaso de un pueblo para hacer la Historia" (Cortezón 1956: 77). En particular resultan interesantes os comentarios que fai sobre unha afirmación de Castelao no Sempre en Galiza: "A tradición é a alma eterna de Galiza, que vive no instinto popular e nas entranas graníticas do noso chán. A tradición non é a hestoria. A tradición é a eternidade" (Castelao 1961: 38). Cortezón aposta pola necesidade de abandonar esta perspectiva de que Galicia é "la Tradición contra la Historia" (1956: 63), posto que, segundo el, esta afirmación "contiene una gran verdad de raiz y que toda la historicidad gallega reposa en grado sumo sobre una inhibición de Historia y una hiperestesia tradicionalista, una hipobiosis" (1956: 76). A tradición é "anquilosamiento, debilidad y necrofagia: en realidad, vive, pues, sin justificante de su propio existir, tratando de aplicar ahora fórmulas que sirvieron antes" (1956: 96) e, retomando os conceptos empregados no ensaio anterior, o noso autor propón superar "el estudio yin de nuestro ser y nuestra cultura para encauzarlo en una dinámica yang", porque o "importante es lo que se es y lo que se quiere ser, no lo que se ha sido, como pretende la última consecuencia del tradicionalismo" (1956: 77).

Non podía faltar tampouco nesta Pantocrítica un apartado dedicado á saudade, e a condena de Cortezón é, como non podía ser doutro xeito, aínda máis radical e implacable:

(...) hay que aniquilar a la Saudade porque toda la "originalidad" que ella nos procura es a costa de nuestra vida, vive de nuestra muerte, de nuestra agonía como pueblo, de nuestro tradicionalismo histórico cristalizado y mitizado en élla y alentado por esa búsqueda inconsciente (o muy consciente) de los motivos justificadores de la "queja" y de su consiguiente presencia "existencial". (1956: 112)

Aparecen de novo os conceptos de "avidalismo", "queixa", "laio", pero o verdadeiramente significativo é que, para Cortezón, toda esta retórica sentimental serve para xustificar a inhibición á hora de actuar politicamente. A súa aposta é por un concepto de progreso que poderiamos cualificar de hegeliano, realmente agresivo, que para el é "un arma de la izquierda política":

lo que es indispensable hacer es que el instinto se convierta en conocimiento, la poética en ciencia y el conservadurismo estático en agresividad dinámica; es decir: todo lo que es Historia e Historia presente, actual, viva: para ello hay que aniquilar al espíritu que informó y mantuvo la psicosis de tradición y dar suelta y alas al esprítiu soterrado capa de hacer historia "urbana" (...). (1956: 77)

(...) Puede ser que nuestro proletariado rural tenga entonces menos arelas, saudades morriñas, señardades e inquedanzas; pero tendrá más pan, más riqueza y menos servidumbre social. (1956: 120) 
Na realidade, e como permitiría comprobalo unha interpretación da novela $A$ vila sulagada (1981), a definición e a interrelación de conceptos como sentimento, razón, progreso ou mesmo historia é moito máis complexa e ambigua, isto é, máis inzada de arestas e contradicións do aquí exposto. Así, ao final da Pantocrítica remata por deixar espazo para unha visión conciliadora entre sentimento e razón: “(...) si nuestro cuerpo cultural y social funciona de manera adecuada y sana, habrá una equipolencia entre el espíritu poético y la técnica científica del cultivo o la construcción de tractores; (...) Saudade a la par que Ciencia" (1956: 122).

O verdadeiro celme da obra filosófica de Daniel Cortezón constitúeo o ensaio De la saudade y sus formas (1960), premiado e publicado en Nova York, do que cabería destacar a fonda crítica á que somete o existencialismo. Recordemos que é nesta corrente filosófica onde Ramón Piñeiro situara as raíces das posibilidades gnoseolóxicas da saudade, mais para o ribadense, que para entón xa lera $O$ asalto á razón (1954) de György Lukács, as posicións existencialistas son radicalmente anticientíficas e irracionais. Así mesmo, volve a explicitar as relacións entre saudade, tradición e historia:

Ser en la Saudade no, porque es lo que hemos sido hasta ahora y ya sabemos que ser en la Saudade es no ser para la Historia, es escabullirse eternamente en el tortuguismo creador, en la hibernación espiritual de la tradición. Tenemos que ser y serlo efectivamente para el hacer y el crear, y para el conquistar, aunque sea a costa de renunciar a profundos amores y bellos sentimientos. (Cortezón 1960: 163)

Tamén insiste no que xa apuntamos como característico de Daniel Cortezón: a súa teima nun concepto "plástico" e aberto da historia e da identidade nacional: "No importa que sea preciso sacrificar lo enxebre: insistimos en que la Historia es un asesinato de verdades, esto ya ha sido dicho por otros. No hay nada de substancia e insubstituible en lo enxebre: lo substancia de Galicia es Galicia misma" (1960: 165).

Finalmente, no longo artigo titulado Sobor das condicións do asalto á razón (1990) a lóxica antisentimental e antirracional leva a Cortezón ao extremo de localizar nas mesmas propostas nacionalistas ás que el contribuiu durante toda a súa vida o perigo de que, precisamente pola súa radicación no sentimento, podan ser instrumentalizadas pola reacción:

(...) pola súa mesma orixe emocional (sangue-terra-matria-lingua) os nacionalismos levan en si un perigoso compoñente "irracional" e un compoñente "racista" que lle é do seu mais doado intrumentalizar á "clase" detentadora do pensamento da dereita: ou, o que é máis: que os nacionalismos - pasada a eclosión liberadora, a radicalización reivindicadora do "memorial de agravios"- entran de cheo no que poidéramos chamar reductos e valores sicolóxicos da dereita, "ideoloxías" da dereita, polo demáis sempre disposta a verquer bágoas sentimentais cantarolando o arume dos pinos e faguendo queimadas folkóricas ó son de mil cincocentos gaiteiros. (1990: 36-37)

Agardamos que estas consideracións contribúan á reivindicación dunha figura marxinada que se caracterizou -e fago miñas as verbas de Roberto Vidal Bolaño- pola "súa non acomodación a modas ou a tendencias", pola "súa valentía á hora de se enfrontar á nosa propia historia", así como pola "fidelidade a si mesmo", o que non é pouca cousa. 


\section{REFERENCIAS BIBLIOGRÁFICAS}

Abuín, Anxo (1999): “A traxectoria teatral de Daniel Cortezón: cara a unha poética do drama histórico galego", en D. Cortezón, Xelmírez ou a gloria de Compostela. Santiago de Compostela: IGAEM.

Bernárdez, Carlos L. et al. (1999): Literatura galega: século XX. Vigo: A Nosa Terra.

Castelao, Afonso Daniel (1961): Sempre en Galiza. Bos Aires: As Burgas.

CorTezón, Daniel (1955): O esprito da Galiza (Manuscrito inédito).

- (1956): Pantocrítica galiciana y otras cuestiones (Manuscrito inédito).

_ (1960): De la saudade y sus formas. Nova York: Casa de Galicia.

(1962): Ouservacións pra unha crítica encol do avidalismo na poesía galega aitoal. (Manuscrito inédito). 34-37.

(1970-71): "Del posible teatro gallego", Casa Galicia. Unidad gallega. Nova York, pp.

(1978): Os Irmandiños. Sada: Ediciós do Castro.

(1990): “Sobor das condicións do asalto á razón”, Cadernos ribadenses 2, pp. 24-37.

(1999a): "Un proxecto teatral inconcluso", en D. Cortezón, Xelmírez ou a gloria de Compostela. Santiago de Compostela: IGAEM.

(1999b): Xelmírez ou a gloria de Compostela. Santiago de Compostela: IGAEM.

Gómez, José (2005): “Entrevista: Daniel Cortezón”, Diario de Ferrol 344, pp. 2-4.

Miguélez-Carballeira, Helena (2013): Galicia, a Sentimental Nation. Cardiff: University of Wales Press.

Pascual, Roberto (2008): "Daniel Cortezón. Lembranzas dunha vida autodidacta", Madrygal 11, pp. 199-205.

PIÑEIRo, Ramón (2001): Filosofía da saudade. A Coruña: La Voz de Galicia.

Risco, Vicente (1994): Obras completas 4. Vigo: Galaxia.

VILAVEDra, Dolores (1999): Historia da literatura galega. Vigo: Galaxia. 